УДК 811.111

ББК 81.2

DOI: https://doi.org/10.17308/lic.2020.1/2734

\title{
АНАЛИЗ ЛИНГВОСТИЛИСТИЧЕСКИХ ОСОБЕННОСТЕЙ АНГЛОЯЗЫЧНОГО ПОСТМОДЕРНИСТСКОГО РОМАНА
}

\author{
Ю. В. Акимцева \\ Тульский государственный педагогический университет имени Л. Н. Толстого \\ А. Ю. Исаева \\ Тульский государственный университет

\begin{abstract}
ANALYSIS OF LINGUISTIC AND STYLISTIC FEATURES OF THE ENGLISH POSTMODERN NOVEL
\end{abstract}

\author{
Yu. V. Akimtseva \\ Tula State Lev Tolstoy Pedagogical University \\ A. Yu. Isaeva \\ Tula State University
}

\begin{abstract}
Аннотация: термин «постмодернизм» за последнее время приобретает новые коннотации в связи с выросшим интересом к данному феномену. Такой интерес объясняется несколькими факторами. Во-первых, влияние постмодернизма на языковую систему и сознание играет одну из ключевых ролей в формировании картины мира, во-вторых, постмодернизму свойственно объединение культурных кодов и текстов разных эпох, что позволяет расширить ранее устаревшие представления о мире. Не менее важным фактором является изменение традииионных понятий о целостности, законченности, структуре текста и новый взгляд на формирование критериев и норм текста. Эти факторы занимают центральную позицию в постмодернизме и создают асистематическое представление о литературном направлении. Данная статья посвящена анализу лингвостилистических особенностей англоязычного постмодернистсткого романа на материале произведения И. Макьюэна «Искупление». Постмодернистский роман является своеобразным литературным направлением, обладающим нетрадииионным подходом к построению художественного текста, что проявляется в применении различных стилистических и лингвистических приемов. В отличие от других литературных направлений постмодернизм воссоздает современную картину мира с ее культурно-бытовыми особенностями. Рассмотрение лингвостилистической специфики постмодернистского романа позволяет выявить характерные черты постмодернизма не только как литературного направления, но и лингвистического. Изучение лингвостилистических черт постмодернистского романа позволяет выделить основные приниипы построения художественного произведения, а именно деконструкиию, интертекстуальность, гипертекстуальность, иронию, мнгоуровневость текста, языковую игру, плюрализм, неопределенность. Эти принииь лежат в основе любого постмодернистсткого романа и представляют собой своеобразный симбиоз кониепџии автора, направленный на взаимодействие с читателем.
\end{abstract}

Ключевые слова: лингвостилистические особенности, постмодернизм, постмодернистский роман, И. Макьюэн, сознание, текст, межпарадигмальное мыиление.

Abstract: the term «postmodernism» has recently acquired new connotations in connection with the increased interest in this phenomenon. There are several reasons for this interest. Firstly, the influence of postmodernism on the language system and consciousness plays a key role in shaping the picture of the world, and secondly,

(C) Акимцева Ю. В., Исаева А. Ю., 2020

Контент доступен под лицензией Creative Commons Attribution 4.0 License.

The content is available under Creative Commons Attribution 4.0 License. 
postmodernism is characterized by the union of cultural codes and texts of different eras, which allows to expand previously outdated ideas about the world. No less important factor is the change of traditional concepts of integrity, completeness, structure of the text and a new view on the formation of criteria and norms of the text. These factors occupy a central position in postmodernism and create an unsystematic representation of the literary direction. This article is devoted to the analysis of linguistic and stylistic features of the English postmodern novel by the material of I. McEwan's work «Atonement». Postmodern novel is a kind of literary direction, which has an unconventional approach to the construction of literary text, which is manifested in the use of various stylistic and linguistic techniques. Unlike other literary trends, postmodernism recreates the modern picture of the world with its cultural and everyday features. Consideration of the linguistic and stylistic specificity of the postmodern novel reveals the characteristic features of postmodernism not only as a literary direction, but also as a linguistic one. The study of the linguistic and stylistic features of the postmodern novel allows us to identify the basic principles of construction of a work of fiction, particularly deconstruction, intertextuality, hypertextuality, irony, multi-level text, language play, pluralism, uncertainty. These principles are the basis of any postmodern novel and represent a kind of symbiosis of the author's concept aimed at interaction with the reader.

Key words: linguostylistic features, postmodernism, postmodern novel, I. McEwen, consciousness, text, interparadigm thinking.

Постмодернизм является литературным направлением с характерным интеллектуальным стилем, отличающимся высоким рефлексивным потенциалом. Несмотря на тот факт, что данное литературное направление зародилось в начале 1980-х гг., постмодернизм сумел занять свою нишу в лингвистике, литературоведении, социологии, философии. В связи с этим постмодернизм неоднократно становится темой многих научных исследований, позволяющих раскрыть сложность и противоречивость данного литературного феномена [1-5].

Возникший интерес к постмодернизму объясняется его несоответствием традиционным устоям формирования художественного текста. Другими словами, постмодернизм представляет собой антитрадиционное направление в литературе с измененным осознанием быта и культуры [3, с. 194]. Одной из основных черт постмодернизма является отрицание идеологических установок модерна [5]. В современном обществе постмодернизм отражает постиндустриальный мир, в центре которого находится эпоха массовой культуры с ее потребительскими ценностями.

Фактическим материалом исследования послужил знаменитый роман И. Макьюэна «Искупление», принесший всемирную известность британскому писателю. Данное произведение представляет особую ценность для литературного направления периода постмодернизма.

Цель настоящей статьи заключается в выявлении лингвостилистических особенностей англоязычного постмодернистского романа на материале произведения И. Макьюэна «Искупление». Считается, что именно этот постмодернистский роман является визитной карточкой писателя, что обусловлено стилистикой текста, заметно отличающейся от его предыдущих работ. Данный аспект и связанная с ним актуальность определили выбор темы исследования.
Для реализации поставленной цели использовались такие методы исследования, как имманентный анализ, интертекстуальный анализ, семантико-стилистический анализ.

Существует большое количество трактовок постмодернизма, что подтверждает его неоднозначность. Прежде чем изучить лингвостилистические особенности данного литературного течения, рассмотрим основные интерпретации постмодернизма с позиции различных научных отраслей.

Философская точка зрения о постмодернизме прослеживается в трудах итальянского философа Умберто Эко, считающего, что постмодернизм выражает духовное состояние, некую художественную волю. Системность и иерархичность уступает место воссозданной многомерной реальности, которая вербализуется различными языковыми средствами $[6$, с. 90].

Лингвистический постмодернизм представляет собой направление, возникшее в результате другого видения структуралистских и постструктуральных традиций в лингвистике XXв. Голландский представитель постмодернизма Д. Фоккема полагает, что постмодернизм обладает достаточно исключительным и неординарным взглядом на мир [7]. В связи с этим вводится принцип нониерархии. Данный принцип находится в основе всех структурообразований постмодернистских объектов, любого постмодернистского кода. Постмодернистский код характеризуется как система селективного выбора семантических и синтаксических средств. В отличие от других кодов постмодернистский код частично игнорирует правила других кодов. В процессе осмысления принципа постмодернистского кода Д. Фоккема применяет термин нонселекции, реализующейся на всех уровнях анализа, т. е. на лексемном уровне, уровне семантических полей, фразовых и текстовых структур [Ibid., p. 80].

Французский представитель лингвистического постмодернизма Ж. Деррида формирует концепцию 
деконструкции, основными категориями которой являются сознание и текст.

Ключевыми понятиями лингвистического постмодернизма являются постмодерн, деятельность, языковое сознание, культура, язык. Как отмечает Ж. Деррида, под постмодерном подразумевается социокультурная ситуация потери согласованности и организованности между разнородными явлениями. Под деятельностью понимается единство дискурсивных практик. Центральной проблематикой данного направления является вопрос о языке и языковом характере мышления. Постмодернистское направление формирует новую систему ценностей, где культура представляет собой систему знаков; языковое сознание характеризуется как психический инструмент осмысления знаков. Язык представляет собой механизм ориентирующего характера, акцент в котором приходится на текст. Возникает новое понятие «нарративизация», связанное со способностью личности к описанию себя, своего опыта. При этом такое описание характеризуется связностью и построением согласно жанрам построения текста [8, р. 5]. В дальнейшем ученый Ж. Лакан создает теорию о текстуализации языкового сознания. Ж. Лакан выдвигает идею о взаимосвязи «воображаемого» и «символического». Согласно его теории, существует три уровня формирования сознания: воображаемое, символическое и реальное. «Воображаемое» реализуется на доязыковом этапе, «символическое» связано с предметами и их взаимосвязью. Наиболее трудным для понимания является «реальное», поскольку его деятельность осуществляется за пределами языка [9]. Впоследствии эта теория была поддержана М. Фуко, полагающим, что три вышеназванных уровня сознания являются операционными дискурсивными системами, названными «эпистемами» [10].

К основным характерным чертам постмодернистского периода можно отнести следующие аспекты:

- разное восприятие (читатель не всегда способен воспринять авторский смысл без искажения);

- дисимметрия языка;

- интерлокуция;

- интерсубъективность;

- межпарадигмальное мышление;

- синергетический плюрализм [9].

Рассмотрев вышеперечисленные характеристики постмодернистского периода, отметим, что центральную позицию занимает мысль о межпарадигмальном мышлении, в сильной позиции которого находится нелинейность, неоднозначность, метафоричность, незавершенность, диалогичность, гипертекстуальность, интертекстуальность.

Выявленные характеристики влияют на особенности постмодернистского романа, поскольку они лежат в основе каждого художественного произведе- ния этого периода. Характерные черты постмодернистского периода формируют правила построения художественного произведения.

Постмодернистские художественные произведения всегда привлекают внимание ученых, поскольку представляют собой некий диалог бессознательного с сознательным, взаимодействие автора и читателя.

Необходимо отметить, что постмодернизм воспроизводит тексты «вне времени». При этом автор такого текста исполняет не главную роль, но в то же время невидимо для читателя создает некие шифры (коды), которые необходимо расшифровать для осознания происходящих событий в произведении.

Ранее было отмечено, что для постмодернистских романов характерны такие черты, как интертекстуальность, гипертекстуальность, диалогичность, неоднозначность, незавершенность. Таким образом, при реализации практической части исследования возникает вопрос о наличии или частичном отсутствии вышеуказанных отличительных признаков стандартного постмодернистского произведения в романе И. Макьюэна «Искупление».

При анализе англоязычного постмодернистского романа «Искупление» были выявлены следующие лингвостилистические особенности.

1. Интертекстуальность.

По утверждению М. М. Бахтина, интертекстуальность представляет собой диалог текстов, цитаты которых образуют единое целое [11, с. 104]. В анализируемом произведении данный прием проявляется в использовании аллюзии, цитации, аппликации, пародии и многих других языковых средств выразительности.

Так, например, автор применяет аллюзию на одного из героев У. Шекспира из «Двенадцатой ночи»:

"At the outer reaches of the desk, various photographs: the cast of Twelfth Night on the college lawn, himself as Malvolio, cross-gartered" [12, p. 82].

Один из главных героев, Робби, будучи влюбленным в Сесилию, полностью меняется. Им овладевают ранее неизвестные ему чувства, которые видоизменяют внутреннее состояние героя и заставляют его совершать опрометчивые поступки, приводящие впоследствии к судьбоносному конфликту, в результате чего меняется жизнь героя.

2. Многоуровневость текста.

Многоуровневость текста распознать достаточно непросто. Считается, что не каждый читатель способен выявить такой прием в тексте. Текст состоит из трех составляющих: художественных приемов (метафора, метонимия, символ, эпитет), образов (герои непосредственно), целостного континуума (сюжетно-композиционный, пространственно-временной и архитектонический).

В письмах главных героев прослеживаются отсылки на персонажей других романов «Тристан и 
Изольда» («Tristan and Iseult», VIII в.), «Троил и Крессида» («Troilus and Cressida», 1602-1609). Робби ассоциирует себя с Прометеем, а Сесилия - с Гризельдой. Таким образом, читатель, зная эти легенды, декодирует послание автора.

3. Ирония как концептуальная категория художественного текста.

Ирония как языковое и концептуальное явление реализуется в тексте в качестве стилистического приема, а также на текстовом уровне. При рассмотрении иронии как концептуальной категории отмечается, что данному явлению характерна авторская концепция, которая реализуется на уровне языка и сознания. При этом отличительной чертой концептуальной иронии является соотношение языкового и экстралингвистического уровней [13, с. 27].

"Poor vain and vulnerable Lola with the pearlstudded choker and the rose-water scent, who longed to throw off the last restraints of childhood, who saved herself from humiliation by falling in love, or persuading herself she had, and who could not believe her luck when Briony insisted on doing the talking and blaming. And what luck that was for Lola - barely more than a child, prised open and taken - to marry her rapist" [12, p. 324].

Брайони, одна из главных героинь, говорит о свадьбе Лолы и насильника, однако посредством иронии автору удается реализовать игру с читателем, идея которой заключается в раскрытии авторской концепции только лишь под конец романа. Именно в конце романа читатель узнает, что в действительности муж Лолы не является насильником, и фальшивые обвинения выгодны для Брайони.

4. Фрагментарность.

Постмодернистское направление отличается наличием обособленных фрагментов текста, которые необходимо соединить воедино как пазл, чтобы увидеть полную картину мира.

Роман «Искупление» состоит из трех глав, которые разделяются на многочисленные фрагменты, каждый из которых ведется от лица главных героев, что позволяет воспринимать произведение как единое целое.

\section{5. Неопределенность.}

Почти весь сюжет романа строится на неопределенных ситуациях, выводах героев. Так, например, Брайони, полностью не уверенная в том, что Робби насилует Лолу, дает ложные показания, что приводит к трагедии.

\section{6. Игра.}

Автор постмодернистского направления применяет игру как метод смешения стилей, эпох, посредством которого выражается авторская задумка. Так, в процессе чтения романа «Искупление» возникает мысль, что повествование ведется от третьего лица, однако в конце произведения полученная Брайони критика от рецензента на ее книгу разрушает эту мысль. Таким образом, И. Макьюэн применяет различные литературные формы, создающие эффект непредсказуемости.

В процессе анализа романа И. Макьюэна «Искупление» четко прослеживается характерная атмосфера эпохи постмодернизма. Художественный текст является отражением антитрадиционных установок постмодернистского направления. Тем не менее, несмотря на использование сходных характерных приемов для построения постмодернистской новеллы, а также на наличие присущих всем романам этого направления свойств, художественное произведение И. Макьюэна «Искупление» обладает и несколькими отличительными признаками, которые определяют научную новизну предпринятого исследования.

Прежде всего, речь идет о комбинировании разной стилевой составляющей, которая проявляется при введении персонажей романа, а также при пространственно-временных отношениях в тексте.

Кроме того, в отличие от характерной для всех постмодернистских романов черты незавершенности, художественный текст И. Макьюэна «Искупление» представляет собой логически завершенное произведение с присущей ему когерентностью и когезией. Особенно ярко выражается авторская интеллектуальная стилистика текста.

Важно отметить, что англоязычный роман «Искупление» обладает аналитичностью и широким семантическим контекстом, благодаря чему формируется целостная осмысленная структурная система, реализующая авторскую концепцию, что выделяет данное произведение среди других работ постмодернистского направления.

\section{ЛИТЕРАТУРА}

1. Антипенко Л. Г. Естественнонаучная оценка постмодернистского подхода к лингвистике и литературному творчеству // Язык и текст. 2018. Т. 5. № 2. C. 14-23.

2. Афанасьева Т. Ю. Постмодерн - художественный стиль или философия? // Научные ведомости БелГУ. Серия: Философия. Социология. Право. 2008. № 12 (52). C. 156-163.

3. Маньковская Н. Б. Постмодернизм в эстетике // Философская антропология. 2018. № 1. С. 192-230.

4. Чотчаева М. Ю., Сосновский В. Т. Постмодернизм в культуре и литературе современности // Вестник Адыгей. гос. ун-та. Серия 2: Филология и искусствоведение. 2017. С. 177-182.

5. Маслаков С. В. Постмодерн как социокультурный проект // Общество: философия, история, культура. 2017. № 2. C. 1-3.

6. Коваленко Ю. С., Чернухин А. Ю. Философия и эстетика постмодернизма в романе У. Эко «Имя Розы» // В мире науки и искусства : вопросы филологии, искусствоведения и культурологи : сб. ст. по материалам LXV междунар. науч.-практ. конф. Новосибирск, 2016. 
№ 10 (65). C. 89-100. URL: https://sibac.info/conf/philolog/ $1 \mathrm{xv} / 62020$

7. Fokkema D. The Semantic and Syntactic organization of Postmodernist Text // Approaching Postmodernism. Amsterdam-Philadelphia, 1986. Pp. 80-98.

8. Lewis Ph. The Post-Structuralist Condition // Diacritics. 1982. № 12. Pp. 8-9.

9. Алефиренко Н. Ф. Русистика и современный «лингвистический постмодернизм» // Русский язык : система и функционирование (к 70-летию филологического факультета) : сб. материалов IV Междунар. науч. конф., г. Минск, 5-6 мая 2009 г.: в 2 ч. Минск : РИВШ, 2009. Ч. 1. C. 3-16.

10. Vallois $N$. Michel Foucault and the history of economic thought // OEconomia. 2015.5 (4). Pp. 461-490.

11. Бахтин М. М. Эстетика словесного творчества. М. : Худож. лит., 1979. 412 c.

12. McEwan I. Atonement. Vintage, 2002. 375 p.

13. Петрова О. Г. Типы иронии в художественном тексте : концептуальная и контекстуальная ирония // Известия Сарат. ун-та. Серия Филология. Журналистика. 2011. № 3. С. 25-29.

\section{REFERENCES}

1. Antipenko L. G. Estestvennonauchnaya otsenka postmodernistskogo podkhoda k lingvistike i literaturnomu tvorchestvu [Natural science assessment of the postmodern approach to linguistics and literary creativity] // Yazyk i tekst. 2018. Tom 5. № 2. Pp. 14-23.

2. Afanas'eva T. Yu. Postmodern-khudozhestvenniy stil' ili filosofiya? [Postmodern-art style or philosophy?] // Nauchnye vedomosti BelGU. Seriya: Filosofiya. Sotsiologiya. Pravo. 2008. № 12(52). Pp. 156-163.

3. Man'kovskaya N. B. Postmodernizm v estetike [Postmodernism in aesthetics] // Filosofskaya antropologiya. 2018. № 1. Pp. 192-230.

Тульский государственный педагогический университет имени Л. Н. Толстого

Акимцева Ю. В., кандидат филологических наук, старишй преподаватель кафедры английской филологии

E-mail:mirada91@gmail.com

Тульский государственныий университет

Исаева А. Ю., кандидат филологических наук, доиент кафедры иностранных языков

E-mail: isaeva_anastasia91@mail.ru

Поступила в редакиию 4 октября 2019 г.

Принята к публикачии 27 декабря 2019 г.

\section{Для цитирования:}

Акимиева Ю. В., Исаева А. Ю. Анализ лингвостилистических особенностей англоязычного постмодернистского романа // Вестник Воронежского государственного университета. Серия: Лингвистика и межкультурная коммуникация. 2020. № 1. C. 82- 86. DOI: https://doi.org/10.17308/lic.2020.1/2734
4. Chotchaeva M. Yu., Sosnovskiy V. T. Postmodernizm $v$ kul'ture i literature sovremennosti [Postmodernism in the culture and literature of modern times] // Vestnik Adigeyskogo gosudarstvennogo universiteta. Seriya 2: Filologiya I iskusstvovedenie. 2017. Pp. 177-182.

5. Maslakov S. V. Postmodern kak sotsiokul'turniy proekt [Postmodern as a socio-cultural project] // Obshchestvo: filosofiya, istoriya, kul'tura. 2017. № 2. Pp. 1-3.

6. Kovalenko Yu. S., Chernukhin A. Yu. Filosofiya $i$ estetika postmodernizma v romane U. Eko "Imya Rozy" [The philosophy and aesthetics of postmodernism in U. Eco's novel "The Name of the Rose"] // V mire nauki i iskusstva: voprosy filologii, iskusstvovedeniya i kul'turologii: sb.st. po mater. LXV mezhdunar. nauch.-prakt. konf. №10(65). Novosibirsk: SibAK, 2016. Pp. 89-100. Available at: https://sibac.info/conf/philolog/lxv/62020

7. Fokkema D. The Semantic and Syntactic organization of Postmodernist Text // Approaching Postmodernism. Amsterdam-Philadelphia. 1986. Pp. 80-98.

8. Lewis Ph. The Post-Structuralist Condition // Diacritics. 1982. № 12. Pp. 8-9.

9. Alefirenko N. F. Rusistika i sovremenniy «lingvisticheskiy postmodernizm» [Russian Studies and Modern "Linguistic Postmodernism"] // Russkij yazyk: sistema i funktsionirovanie (k 70-letiyu filologicheskogo fakul'teta): sb. materialov IV Mezhdunar. nauch. konf., g. Minsk, 5-6 maya 2009 g.: v 2 ch. Minsk: RIVSH, 2009. Ch. 1. Pp. 3-16.

10. Vallois N. Michel Foucault and the history of economic thought. OEconomia, 5(4). 2015. Pp. 461-490.

11. Bakhtin M. M. Estetika slovesnogo tvorchestva [Aesthetics of verbal creativity]. M.: Khudozhestvennaya literatura, $1979.412 \mathrm{p}$.

12. McEwan I. Atonement. Vintage. 2002. 375 p.

13. Petrova O. G. Tipy ironii v khudozhestvennom tekste: kontseptual'naya i kontekstual'naya ironiya [Types of irony in a fiction text: conceptual and contextual irony] // Izvestiya Saratovskogo universiteta. Seriya Filologiya. Zhurnalistika. 2011. № 3. Pp. 25-29.

Tula State Lev Tolstoy Pedagogical University

Akimtseva Yu. V., Candidate of Philology, Senior Lecturer of the English Philology Department

E-mail:mirada91@gmail.com

Tula State University

Isaeva A. Yu., Candidate of Philology, Associate Professor of the Foreign Languages Department

E-mail: isaeva_anastasia91@mail.ru

Received: 4 October 2019

Accepted: 27 December 2019

\section{For citation:}

Akimtseva Yu. V., Isaeva A. Yu. Analysis of linguistic and stylistic features of the english postmodern novel. Proceedings of Voronezh State University. Series: Linguistics and Intercultural Communication. 2020. No. 1. Pp. 82-86. DOI: https://doi.org/10.17308/lic.2020.1/2734 